\title{
TRANSPARENCY OF FINANCIAL INFORMATION ON CROWDFUNDING PLATFORMS - A PREREQUISITE FOR SUCCESSFUL FUNDING CAMPAIGNS
}

\author{
Mina FANEA-IVANOVICI \\ University of Economic Studies, Bucharest, Romania \\ mina.ivanovici@economie.ase.ro
}

\begin{abstract}
Crowdfunding, a relatively novel internet-based non-banking funding instrument for startups, innovative, creative or prosocial projects, implies that funders (donors or lenders) and fund seekers (project initiators) interact on a crowdfunding platform. The goal of fund seekers is to raise the necessary amount of money to finance their project, while donors are backers of business or research ideas, social causes or start-up companies. Existing research has proven that for a crowdfunding campaign to succeed, one condition is for the crowdfunding platform to provide the adequate technical functionalities that ensure sufficient financial information both during and after the campaign (such as how the money was used and how the money was returned if the project failed) but also the legal framework through a solid contract between the platform and the fund seeker that can prevent moral hazard of the latter. The purpose of this study is to perform a qualitative analysis of the active crowdfunding platforms in Romania in terms of financial information transparency and to determine whether they fulfil the necessary conditions to ensure fair use of donations by project initiators and distribution of reward to donors.
\end{abstract}

Keywords: crowdfunding, financial transparency, moral hazard, reward-based, donors

\section{Introduction}

Crowdfunding is a relatively novel internetbased non-banking funding instrument, which has been designed mainly for earlystage companies having little financial power and insufficient resources and/or without bank loan eligibility or for nonprofit institutions. Companies usually resort to crowdfunding in order to finance projects involving research ideas or innovative, creative, artistic products and services, while non-profit organisations seek for donations that serve a greater cause prosocial campaigns.

The party seeking funding (the project initiator) displays the project with all its associated details (text description, video etc.) on an internet-based platform called the crowdfunding platform (CFP). Thus, the
CFP is an intermediary between those looking for funding and donors (also called lenders, funders). The goal of the former is to raise the necessary amount of smart money to finance their project. Depending on the crowdfunding type, the funder can be a simple donor (donation without any financial or non-financial benefit), a lender receiving non-monetary benefits (rewardbased crowdfunding), a lender (loan-based crowdfunding) or an investor (equity-based crowdfunding). The present paper will only consider the first two cases and the crowdfunding market in Romania. The reason why the other two types are not dealt with is that they have not yet been legislated in Romania.

The aim of this paper is to present a qualitative analysis performed on the 
content of all the active CFPs in Romania and to determine whether they fulfil the necessary conditions to ensure fair use of donations by project initiators and distribution of reward to donors.

\section{Literature review}

Existing research has shown that for a crowdfunding campaign to succeed, one condition is for the CFP to provide the adequate technical functionalities that ensure sufficient financial information both during and after the campaign. Such information transparency refers to how the money was used, how the money was returned if the project failed or how the promised reward was distributed to donors. Another condition for a successful crowdfunding campaign is the conclusion of a solid contract between the CFP and the project initiator - the latter contract with donors before the payment or investment.

Crowdfunding involves a double switching behaviour [1]: on the one hand, businesses switch from traditional banking services to crowdfunding (for benefits such as: speed, flexibility and simplicity, but also process transparency), on the other hand, consumers choose to invest in various projects based on the economic performance or reward received. Improved transparency on CFPs affords would-be lenders' access to information regarding the behaviour of other investors, which creates an information environment supportive of herding [2]. A specific case of funding via CFPs is that of journalism, whereby ethical issues regarding production transparency and responsiveness are involved. In this context, it is claimed that sometimes accountability is best outsourced and implemented thanks to audience participation [3]. As concerns equity-based crowdfunding, Baucus and Mitteness [4] claim that illegal entrepreneurs are able to circumvent the safeguards aimed at protecting investors: the screening for valuable projects performed by the crowd, transparency and documentation requirements, and independent audit reports. According to Farajian, Lauzon et al., transparency is seen both as a prerequisite for successful crowdfunding campaigns and CFPs and as a strength of this funding alternative as compared to alternative finance means [5]. The same authors claim that among the weaknesses is third-party confidential information, whereas one of the threats is the potential for fraud, which is an example of moral hazard. Renwick and Mossialos [6] also point out that the benefits of crowdfunding include, inter alia, fostering project accountability, risks include fraud and broader threats of market failure stemming from adverse selection and moral hazard apply as well. Moral hazard is managed through conditional pledging behaviour, which reduces demand uncertainty and increased welfare as opposed to traditional financing, which is mostly concerned with controlling moral hazard [7]. Furthermore, because of information asymmetry and adverse selection problem, utilitarian value is relatively hard to satisfy, and that is the reason why the projects with more hedonic value can be more appealing to lenders or donors [8].

\section{Research methodology}

The research method used is a qualitative analysis of the contents existing on all active CFPs in Romania in terms of financial transparency. A total of nine CFPs were identified and considered valid for the present study - active and completed projects are posted on the selected CFPs. The purpose of the study is mainly to establish whether or not Romanian CFPs comply with the basic conditions that ensure fair use and tracking of donations and reward distribution, which in turn determine the success of online funding campaigns. In performing the study, we have analysed the main legal provisions included in the contract signed by and between the CFP and the project initiators, especially those terms referring to the 
payback of all donated amounts if the target is not reached, to rewards and the way they are distributed, how the audience can control and be updated with the development of the project after the campaign. All these measures are meant to mitigate and control entrepreneurial or nonprofit organisation moral hazard.

\section{Findings}

The analysis was performed on all nine Romanian CFPs that were functional at the time of the study. Not all the CFPs have the same target audience, features or type or projects. Two of the CFPs are backed by two important commercial banks operating in Romania and a third one belongs to a public Romanian university. One of the CFPs is additionally involved in raising capital for projects or businesses, not just in projects requiring donations with/without reward, as is the case of all the other CFPs. One of the CFPs working in partnership with a commercial bank is entirely dedicated to serving prosocial projects, while the other one working with a commercial bank aims exclusively at supporting entrepreneurs and their projects.
Irrespective of the main objective and target of the CFP, the type of ownership of the CFP, the partnership they are part of or any other distinguishing feature, of particular interest for this study is the (real-time) financial transparency of each of the CFPs and the terms and conditions regarding all financial aspects related to donations. The hypothesis of the study is that clear and strict terms and conditions - regarding payments, money reimbursement in case of project failure and information on how the money was used - influence the success of a crowdfunding campaign in particular (the project is financed) and the success of the CFP in general - attracting as many projects as possible and having as many completed and financed projects as possible. Table 1 below summarizes the main information on each CFP regarding transactions and how the donor can be updated about the progress of the project, how the money is reimbursed (if the project fails), corresponding bank fees and CFP fees, as well as other information that is useful to ensure successful projects.

Table 1 Available public (including financial) information on the CFPs

\begin{tabular}{l} 
Available public information \\
\hline CFP 1 \\
A project is financed if $100 \%$ of the target is reached \\
If the target is not reached, the money is reimbursed, redirected to other projects or donated to \\
the CFP \\
Update/news section - where project initiators can communicate with the donors \\
CFP fee $7 \%$ of the amount, payment operators fees $2-3 \%$ (the latter are not reimbursed if the \\
project does not reach the target) \\
Duration of projects: 30 to 90 days \\
\hline CFP 2 \\
A project is financed if $100 \%$ of the target is reached \\
If the target is not reached, the money is reimbursed \\
If the project is not financed, it is deleted from the CFP \\
Update/news section \\
CFP fee $6 \%$ of the amount for commercial projects, $0 \%$ for charitable projects \\
No payment fee if transactions are made by credit card \\
Duration of projects: 30 to 90 days
\end{tabular}


No public (without logging) information about the CFP policy if the target is not reached

Comments section

No public information about the CFP fees or payment fees

No information regarding the duration of projects

CFP 3

A project is financed if $100 \%$ of the fixed target is reached or if $30 \%$ of the flexible target is reached

If the target $(100 \%$ or $30 \%)$ is not reached, the money is reimbursed

The goal can be exceeded (stretch goals)

The money is transferred to the project within 10 days of the campaign

Update/news section - where project initiators can communicate with the donors and in-site application for private messages between donors and project initiators

The contribution can be withdrawn (except if it changes the status of the campaign, and that only during the last $48 \mathrm{hrs}$ )

CFP fee $6 \%$ of the amount for fixed target, $9 \%$ for flexible target, payment operators fees 2 $3 \%$

Duration of projects: $30-60$ days

Public information about the contract signed between CFP and project initiator to secure reward distribution

\section{CFP 4}

All projects are charitable

No payment fees, not even for small amounts

The donated amounts are updated within $48 \mathrm{hrs}$

The project initiator receives real-time notifications with details about all payments and donors

The money is transferred to the project initiator in the first half of the month for the previous month

\section{CFP 5}

A project is financed if $100 \%$ of the target is reached

If the target is not reached, the money is reimbursed

CFP fee $6 \%$ of the amount, payment operators fees 3-5\% (all fees are reimbursed if the project reaches the target)

\section{CFP 6}

No reimbursement because all the money will be used for the project

Maximum amount that can be donated RON 25,00

All donations are made by credit card

\section{CFP 7}

There is no reimbursement, the money is transferred to the project initiators in all cases Update/news section

CFP fee $5 \%$ of the amount if the target is reached, $9 \%$ of the amount if the target is not reached. Discounted fees by $20 \%$ for NGOs (4\% for successful campaigns, $7.2 \%$ if the target is not reached)

Duration of projects: 1-60 days 


\section{CFP 8}

A project is financed if $100 \%$ of the target is reached

If the target is not reached, the money is reimbursed

No public (without logging) information about the CFP fee

Payment operators fees $0 \%$

The first conclusion is that there are two types of financing policy: one in which all the money is reimbursed if the target is not reached (used by the majority of CFPs), and one in which the money is still transferred to the project initiator, no matter the result of the campaign. A flexible target is justified whenever certain projects can still be implemented in a lower-cost scenario. The first type of policy fosters confidence in donators and motivation for project initiators to promote the project and reach the target. The condition to reach the target obliges the project initiator to estimate correctly the budget and the financial objective. The CFP opting for the second type of policy still applies a CFP fee, even higher than that in case of success, which is meant to penalise the unsuccessful campaign. While the first policy is meant to protect the donors' interests - ensuring all efforts are made to implement the project, the second one is more likely to attract project initiators, who might have other financing sources besides the CFP donations. An investigation on the latter proves the hypothesis - the CFP with noreimbursement option attracts large numbers of projects.

In certain cases, donations can be withdrawn, which is an option that could deter project initiators from posting their project on that specific CFP. Indeed, the only CFP applying this policy is currently (and historically) short of projects. Such a term could endanger the success of the project - the amount displayed on the website informs the public the target has been reached, but instead the donor withdraws the donation and the status of the campaign becomes not financed from financed. By contrast, most CFPs allow the donations to be paid after reaching the $100 \%$ target. The additional money is pledged to be used for the stated purpose and it can improve the quality or quantity of goods and/or services to be provided stretch goals.

Platforms set a typical duration for projects between 30 and 90 days, which is common for this type of reward-based or donation crowdfunding. Moreover, the CFP publicly and clearly stating that all efforts are made for the money to be used for the intended purpose by drafting a solid contract between the CFP and the project initiator has a large number of donor and projects as well.

The existence of a news/updates section is first meant for the donor to communicate with the project initiator during the campaign, but also after the campaign, which is a good measure and functionality meant to prevent moral hazard on behalf of the project initiator. Accountability is thus shared between the CFP (through the contract and various checks) and the public or audience (who are permanently in touch with the project initiator). Such communication means also ensure that the donor can receive information about the progress of the project and the estimated time when the reward is to be obtained. The CFPs having a separate (usually right-hand side) section describing the types of rewards are the most popular (attracts visitors and donors on the web site), unlike CFPs on which such information is made available only after logging in or creating an account. If the reward is a product, then its value should be close to its real cost. If the reward implies a unique experience or limited editions, then its value depends on the audience.

Last but not least, lacking information about the CFP or payment fees prevent project initiators from posting the project. The financial information should be 
available to all sorts of visitors and known just by those creating an account. The same is true of lacking information regarding the deadline until payment is made (in number of days from the completion of the campaign). On the contrary, all CFPs presenting information about payment deadline attract numerous ongoing projects. Needless to say, no payment fees or the existence of payment notifications and updates to project initiators are both factors that determine project initiators to choose a certain CFP.

\section{Conclusions}

The present study discusses the main determinants of successful CFPs and crowdfunding campaigns in terms of available financial and technical information, which are crucial both for donors and for project initiators. The main risks associated with this type of financing are: change in the behaviour of the project initiator upon completion of the project or change of mind of the donor, when there is an option for the donor to withdraw the donation, thus imperilling the status of the project. The findings of the study also encompass the main factors influencing the choice of a certain platform by project initiators, which depends on the CFP functionalities, policies and available information, but also the main factors and assure or reassure donors into paying contributions/donations. By analysing each CFP separately, there has been found a direct correlation between the availability and sufficiency of such information on the CFP and the number of posted projects and activity (comments, news) on the respective CFP.

\section{References}

[1] Maier, Erik, "Supply and Demand on Crowdlending Platforms: Connecting Small and Medium-sized Enterprise Borrowers and Consumer Investors", Journal of Retailing and Consumer Services, Vol. 33, pp. 143-153, 2016.

[2] Wang, Jun, Mao, Xinwei et al., Is There Herding in Reward-based Crowdfunding?, 2016 PPH International Conference on Social Science and Environment, Vol. 1, pp. 6772, Vancouver, Canada, January, 2016.

[3] Porlezza, Colin and Splendore, Sergio, "Accountability and Transparency of Entrepreneurial Journalism. Unresolved Ethical Issues in Crowdfunded Journalism Projects”, Journalism Practice, Vol. 10, No. 2, pp. 196-216, 2016.

[4] Baucus, Melissa and Mitteness, Cheryl, "Crowdfunding: Avoiding Ponzi Entrepreneurs When Investing in New Ventures”, Business Horizons, Vol. 59, No. 1, pp. 37-50, 2016.

[5] Farajian, Morteza, Lauzon, Alexandra J. et al., "Introduction to a Crowdfunded PublicPrivate Partnership Model in the United States Policy Review on Crowdfund Investing", Transportation Research Record, No. 2530, pp. 36-43, 2015.

[6] Renwick, Matthew J. and Mossialos Elias, "Crowdfunding Our Health: Economic Risks and Benefits", Social Science \& Medicine, Vol. 191, pp. 48-56, 2017.

[7] Strausz, Roland, "A Theory of Crowdfunding: A Mechanism Design Approach with Demand Uncertainty and Moral Hazard", American Economic Review, Vol. 107, No. 6, pp. 1430-1476, 2017.

[8] Zhao, Liang and Vinig, Tsvi, "Hedonic Value and Crowdfunding Project Performance> a Propensity Score Matching-Based Analysis", Review of Behavioral Finance, Vol. 9, No. 2, pp. 169-186, 2017. 